Full Length Article

\title{
Experimental use of an acrolein-based primer as collagen cross-linker for dentine bonding
}

\author{
Tatjana Maravic $^{\mathrm{a}, \mathrm{b}}$, Lorenzo Breschi ${ }^{\mathrm{a}, *}$, Allegra Comba ${ }^{\mathrm{a}}$, Sandra Ribeiro Cunha ${ }^{\mathrm{a}, \mathrm{c}}$, \\ Valeria Angeloni $^{\mathrm{d}}$, Cesare Nucci $^{\mathrm{a}}$, Josimeri Hebling ${ }^{\mathrm{e}}$, David Pashley ${ }^{\mathrm{f}}$, Franklin Tay ${ }^{\mathrm{f}}$, \\ Annalisa Mazzoni ${ }^{\text {a }}$ \\ a Department of Biomedical and Neuromotor Sciences, DIBINEM, University of Bologna - Alma Mater Studiorum, Bologna, Italy \\ b School of Dentistry, Faculty of Medicine, University of Novi Sad, Novi Sad, Serbia \\ ${ }^{\mathrm{c}}$ Department of Restorative Dentistry, School of Dentistry, University of São Paulo, São Paulo, Brazil \\ d Private Practice, Imperia, Italy \\ e Department of Pediatric Dentistry and Orthodontics, Araraquara School of Dentistry, UNESP - University of Estadual Paulista, Araraquara, SP, Brazil \\ ${ }^{\mathrm{f}}$ The Dental College of Georgia, Augusta University, Augusta, GA, USA
}

\section{A R T I C L E I N F O}

\section{Keywords:}

Acrolein

Collagen cross-linkers

Hybrid layer durability

Matrix metalloproteinases

\begin{abstract}
A B S T R A C T
Objectives: The objective of the present study was to investigate the long-term effect of $0.01 \%$ acrolein (ACR) aqueous solution, employed as an additional primer, on the mechanical durability and enzymatic activity of resin-dentine interfaces created with a simplified etch-and-rinse adhesive.

Methods: Dentine surfaces were etched with 35\% phosphoric acid for $15 \mathrm{~s}$, rinsed and blot-dried. Specimens were then assigned to: Group 1: dentine pre-treated with $0.01 \%$ ACR aqueous solution for 1 min and bonded with Adper Scotchbond 1 XT (SB1XT), a 2-step etch-and-rinse adhesive; Group 2: SB1XT was applied on untreated acid-etched dentine (control). Resin composite build-ups were made using Filtek Z250. Microtensile bond strength was tested by stressing sectioned specimens to failure immediately or after 1 year of storage in artificial saliva at $37^{\circ} \mathrm{C}$. Zymography and in-situ zymography assays were performed for examining dentine matrix metalloproteinase (MMP) activities.

Results: The use of $0.01 \%$ ACR as conditioning primer appeared to have contributed better to preservation of bond strength over time without affecting immediate bond strength. Zymography and in-situ zymography showed reduction in MMP activities after the application of ACR.

Conclusion: Dentine collagen cross-linking produced by an ACR-based primer increases the longevity of resindentine bonds by reinforcement of the adhesive interface and reduction of dentine MMP activities. Further studies are required to evaluate the potential in vivo and in vivo cytotoxicity of ACR.

Clinical significance: The acrolein-based primer is a potentially useful clinical bonding tool because it demonstrates good collagen cross-linking ability within a clinically-acceptable working time. Although a low ACR concentration was employed in the present study, the cytotoxicity of ACR should be tested prior to clinical use.
\end{abstract}

\section{Introduction}

The stability and integrity of collagen fibrils within the hybrid layer is crucial for the maintenance of long-term bonding effectiveness in adhesive dentistry $[1,2]$. Type I collagen accounts for approximately $90 \%$ of the dentine organic matrix $[1,3]$. The collagen fibrillar network forms the organic framework of dentine within which intrafibrillar and extrafibrillar apatite crystallites are deposited. Matrix metalloproteinases (MMPs) are zinc- and calcium-dependent endopeptidases that are trapped within the mineralised dentine matrix during tooth development [4]. These endogenous enzymes are responsible for in vitro and in vivo degradation of the hybrid layer, via hydrolysis of collagen fibrils that are not completely encapsulated by polymerised adhesive resins [5-7]. Disruption of resin-dentine integrity caused by the degradation of the hybrid layer accounts for the loss of bond strength over time.

Different strategies have been proposed to minimise degradation of the hybrid layer over time. These strategies include reinforcement of the collagen fibrils within the hybrid layer, inhibition/inactivation of endogenous enzymes, or a combination of these two strategies $[1,8,9]$.

\footnotetext{
* Corresponding author at: Department of Biomedical and Neuromotor Sciences, DIBINEM, University of Bologna - Alma Mater Studiorum, Via San Vitale 59, 40125, Bologna, Italy.

E-mail address: lorenzo.breschi@unibo.it (L. Breschi).
} 
Based on the premises that native cross-links improve the tensile properties of collagen fibrils and increase the resistance of a collagen matrix against enzymatic degradation [10], different natural and chemical cross-linking agents have been used experimentally to increase cross-linking of a demineralised collagen matrix prior to adhesive application [11-17]. Collagen cross-linking agents have the ability to reinforce the collagen fibrils network by inducing intra- and intermolecular cross-links; recently published studies showed that some of these agents are also capable of inactivating dentinal MMPs [11,12].

Aldehydes such as glutaraldehyde stabilise collagen fibrils in several connective tissues and improve the mechanical properties of dentine [13-15]. Acrolein (2-propenal; ACR), the simplest unsaturated aldehyde, has been used for controlling aquatic weeds in irrigation canals, as a burrow fumigant to control rodents, and as a microbiocide to eliminate slime-forming microbes in oil drilling operations, pulp and paper mills $[21,22]$. Similar to glutaraldehyde, the electrophilic ACR is a strong cross-linking agent of cellular components such as proteins [23], forming carbonyl-retaining Michael adducts with protein molecules that may be attacked by adjacent protein nucleophiles to form intermolecular cross-links [24]. Hence, it is anticipated that ACR, when used in a diluted concentration, may have potential use as collagen cross-linker in dentine bonding involving the etch-and-rinse technique. Accordingly, the objective of the present study was to investigate the long-term effect of the use of 0.01 ACR wt\% aqueous solution as an additional primer, on the mechanical durability of resin-bonded dentine created with a simplified etch-and-rinse adhesive. Zymography of dentine extracts and in-situ zymography of resin-dentine interfaces were additionally performed to analyse the potential inhibition effect of ACR on dentinal MMPs. The null hypotheses tested were that the use of ACR as a collagen cross-linker: 1) has no effect on bond strength deterioration over time and 2) has no effect on inactivation of endogenous dentine MMPs.

\section{Materials and methods}

\subsection{Microtensile bond strength}

Thirty-six extracted non-carious sound human third molars were collected after the patients' informed consents were obtained under a protocol approved by the institutional review board of the University of Bologna, Italy. Tooth crowns were removed with a low-speed diamond saw under water irrigation (Micromet, Remet; Bologna, Italy) to expose coronal dentine that was devoid of occlusal enamel. A standardised smear layer was created on the middle/deep coronal dentine with 180grit wet silicon carbide paper. The exposed dentine surfaces were etched with 35\% phosphoric acid for $15 \mathrm{~s}$ (etching gel, $3 \mathrm{M}$ ESPE; St Paul, MN, USA), rinsed with water, gently air-dried and kept moist until the adhesive was applied using the wet-bonding technique. The teeth were divided and randomly assigned to 2 treatment groups $(n=18)$. In group 1 (experimental), the acid-etched dentine was pre-treated with 0.01 ACR wt $\%$ aqueous solution (MilliporeSigma, St, Louis, MO, USA) for $1 \mathrm{~min}$, gently air-dried and bonded with Adper Scotchbond 1XT (3 M ESPE) in accordance with the manufacturer's instructions. The composition of the adhesive is shown in Table 1. In group 2 (control), Adper Scotchbond 1XT was applied directly on the etched dentine in accordance with manufacturer's instructions. In both groups, the

Table 1

Composition of Adper Scotchbond 1 XT.

$$
\text { Composition }
$$

Etching:

Adhesive:

$35 \% \mathrm{H}_{3} \mathrm{PO}_{4}$

dimethacrylates, 2-hydroxyethyl methacrylate, polyalkenoic acid copolymer, $5 \mathrm{~nm}$ silane-treated colloidal silica, ethanol, water, photoinitiator adhesive was light-cured (Curing Light 2500; 3 M ESPE) for $20 \mathrm{~s}$ after solvent evaporation. Four 1-mm-thick layers of a microhybrid resin composite (Filtek Z250, 3 M ESPE) were incrementally placed over the bonded dentine surface and individually polymerised for $20 \mathrm{~s}$ to obtain a final $4 \mathrm{~mm}$-thick composite build-up for microtensile bond strength ( $\mu$ TBS) testing.

Resin-dentine sticks were created with a cross-sectional area of approximately $1 \mathrm{~mm} \times 1 \mathrm{~mm}$ from each bonded tooth using the lowspeed saw under water irrigation, in accordance with the protocol for the non-trimming $\mu \mathrm{TBS}$ technique. The dimension of each stick was measured with a pair of digital callipers ( $\pm 0.01 \mathrm{~mm}$ ), and the bonded area was calculated for subsequent conversion of $\mu$ TBS values into units of stress (MPa). Sticks from each tooth were randomly assigned to two storage groups. For time 0 (T0), the sticks were stored in artificial saliva [5] for $24 \mathrm{~h}$ at $37^{\circ} \mathrm{C}$; for time 1 year (T1yr), the sticks were stored for 1 year in artificial saliva at $37^{\circ} \mathrm{C}$.

After storage, the bonded beams were stressed to failure using a simplified universal testing machine (Bisco Inc., Schaumburg, IL, USA) at a crosshead speed of $1 \mathrm{~mm} / \mathrm{min}$. Each specimen was observed under a stereomicroscope (Stemi 2000-C; Carl Zeiss Jena GmbH, Göttingen, Germany) at $50 \times$ magnification to determine the mode of failure, which was classified as adhesive (A), cohesive in composite (CC) or cohesive in dentine (CD).

Analysis was performed using the tooth as the statistical unit; bond strength data from each tooth were averaged to obtain the mean bond strength for that tooth. The acquired data $(\mathrm{n}=18)$ were evaluated for compliance with the normality (Shapiro-Wilk test) and equality of variance (modified Levine test) assumptions required for parametric statistical analysis. Because these assumptions were not violated, the data were analysed with a two-factor analysis of variance, to examine the effects of "with/without ACR" and "storage time" on $\mu$ TBS. Post-hoc pairwise comparisons were conducted using the Holm-Sidak method. For all analyses, statistical significance were set at $\alpha=0.05$.

\subsection{Zymography of dentine extracts}

Zymography was performed using the method employed by Mazzoni et al. [8]. Mineralised dentin powder was obtained from additional eight human third molars by freezing the dentine in liquid nitrogen and triturating it using a Retsch mill (Model MM400, Retsch $\mathrm{GmbH}$, Haan, Germany). Aliquots of mineralised dentine powder were divided in 2 groups. For group 1, the dentine powder was demineralised with $37 \%$ phosphoric acid to simulate the etching procedure used in the application of an etch-and-rinse adhesive. For group 2, the dentine powder was demineralised in the same manner as group 1 and then treated with $0.01 \mathrm{wt} \%$ ACR solution at $4{ }^{\circ} \mathrm{C}$ for $30 \mathrm{~min}$. For the control, after demineralisation with $37 \%$ phosphoric acid, the dentine powder was incubated with $2 \mathrm{mM}$ of 1,10 -phenanthroline at $4{ }^{\circ} \mathrm{C}$ for $30 \mathrm{~min}$.

After the aforementioned treatments, the dentine powder aliquots were suspended in extraction buffer $(50 \mathrm{mM}$ Tris- $\mathrm{HCl}, \mathrm{pH} 6$, containing $5 \mathrm{mM} \mathrm{CaCl}_{2}, 100 \mathrm{mM} \mathrm{NaCl}, 0.1 \%$ Triton X-100, $0.1 \%$ non-ionic detergent P-40, $0.1 \mathrm{mM} \mathrm{ZnCl}$ and $0.02 \% \mathrm{NaN}_{3}$ ) overnight at $4{ }^{\circ} \mathrm{C}$. The powders were subsequently sonicated for $10 \mathrm{~min}$ (at $\approx 30$ pulses) and centrifuged for $20 \mathrm{~min}$ at $4{ }^{\circ} \mathrm{C}(20,800 \mathrm{X} \mathrm{G})$; the supernatants were retrieved and re-centrifuged. The protein content in the supernatants was concentrated using Vivaspin centrifugal concentrator (10,000 KDa cutoff; Vivaspin Sartorius Stedim Biotech, Goettingen, Germany) for $30 \mathrm{~min}$ at $25^{\circ} \mathrm{C}(15,000 \times \mathrm{G}$ for 3 times $)$. Total protein concentration of the dentine extracts was determined by Bradford assay. Dentine protein aliquots $(60 \mu \mathrm{g})$ were diluted with Laemmli sample buffer in a 4:1 ratio. Electrophoresis was performed under non-reducing conditions using $10 \%$ sodium dodecyl sulphate-polyacrylamide gel (SDS-PAGE) containing $1 \mathrm{mg} / \mathrm{mL}$ fluorescent dye-labelled gelatine. Pre-stained lowrange molecular weight SDS-PAGE standards (Bio-Rad, Hercules, CA, USA) were used as reference markers. After electrophoresis, the gels were washed for $1 \mathrm{~h}$ in $2 \%$ Triton X-100, and incubated in zymography 
activation buffer $\left(50 \mathrm{mmol} / \mathrm{L}\right.$ Tris- $\mathrm{HCl}, 5 \mathrm{mmol} / \mathrm{L} \mathrm{CaCl}_{2}, \mathrm{pH}$ 7.4) for $48 \mathrm{~h}$. Proteolytic activity was evaluated and registered with a longwave ultraviolet light scanner (ChemiDoc Universal Hood, Bio-Rad). Gelatinase activities in the specimens were analysed in duplicate using gelatine zymography. Densitometric evaluation of bands obtained from zymography was performed using the ImageJ software (National Institutes of Health, Bethesda, MD, USA).

\subsection{In-situ zymography of resin-dentine interfaces}

One millimetre-thick slabs of middle/deep dentine were obtained from extracted human third molars using the low-speed Micromet saw with water-cooling. A standardised smear layer was created on each dentine surface using 280-grit silicon-carbide paper. One surface of each slab was treated with ACR primer and Adper Scotchbond 1XT adhesive as described for $\mu$ TBS testing. This was followed by a 1-mm build-up with flowable composite (Filtek 250 flow; $3 \mathrm{M}$ ESPE); the composite was polymerised for $40 \mathrm{~s}$ using a light-emitting diode lightcuring unit (Curing Light 2500; $3 \mathrm{M}$ ESPE). After completion of those procedures, the bonded assemblies were sectioned vertically into 1mm-thick slabs to expose the adhesive-dentine interface. Each slab was glued to a microscope slide and polished to the thickness of approximately $50 \mu \mathrm{m}$. In-situ zymography was performed according to the protocol reported by Mazzoni et al. [12], using self-quenched fluorescein-conjugated gelatine as the MMP substrate (E- 12055; Molecular Probes, Eugene, OR, USA). Briefly, the fluorescent gelatine mixture was placed over the polished slab on top of the microscopic slide, covered with a coverslip and incubated in a humidified chamber at $37{ }^{\circ} \mathrm{C}$ for $12 \mathrm{~h}$. During incubation, the assemblies were prevented from direct contact with water, and were protected from exposure to light. After incubation, the microscopic slides were examined using a confocal laser scanning microscope (excitation wavelength, $488 \mathrm{~nm}$; emission wavelength, $530 \mathrm{~nm}$; Model A1-R; Nikon, Tokyo, Japan). For each assembly, a series of $1 \mu \mathrm{m}$-thick two-dimensional images were made to show the hydrolysis of the quenched fluorescein-conjugated gelatine substrate, as indicator of endogenous gelatinolytic enzyme activity. Each image series was subsequently merged into three-dimensional images, providing additional information on the changes in the gelatinolytic activity throughout the depth of the sample. Enzymatic activity was quantified on the images as the integrated density of the fluorescence signals using ImageJ software (National Institutes of Health, Bethesda, MD, USA).

The integrated density of the fluorescence signals was quantified as indicator of the dentine enzymatic activities of the tested groups. Because the data were not normally distributed even after nonlinear transformation, they were analysed using the Mann-Whitney $U$ test, with $\alpha=0.05$.

\section{Results}

\subsection{Microtensile bond strength}

The results of $\mu$ TBS are shown in Table 2 and Fig. 1. The table presents the means and standard deviations of $\mu \mathrm{TBS}$ (in MPa) of groups 1 and 2 at T0 and T1yr, respectively. Two-factor analysis of variance revealed significant difference for the factor "with/without ACR" $(\mathrm{p}<0.001)$ and the factor "storage time" ( $\mathrm{p}<0.001)$. The interaction of these two factors was also statistically significant ( $\mathrm{p}<0.001)$. Within the factor "with/without ACR", pairwise comparisons indicated no significant difference in $\mu$ TBS between the two bonding methods at T0 ( $\mathrm{p}>0.05$ ), and significant difference between the two bonding methods at T1 yr $(\mathrm{p}<0.05)$. Within the factor "storage time" (T0 vs $\mathrm{T} 1 \mathrm{yr}$ ), pairwise comparisons indicated significant decline in $\mu \mathrm{TBS}$ for the subgroups "adhesive only" $(\mathrm{p}<0.05)$ and " $0.01 \mathrm{wt} \%$ ACR + adhesive" ( $\mathrm{p}<0.05)$.
Table 2

Microtensile bond strengths (mean $\pm \mathrm{SD}$, in $\mathrm{MPa}$ ) of group $1(0.01 \%$ acrolein pretreatment) and group 2 (control) immediately after bonding (T0) and after 1 year of ageing (T1yr) in artificial saliva.

\begin{tabular}{lll}
\hline Storage time & Adhesive only & $0.01 \mathrm{wt} \%$ ACR + adhesive \\
\hline T0 & $46.0 \pm 4.9^{\mathbf{A}, 1}$ & $46.6 \pm 3.1^{\mathbf{B}, 1}$ \\
& $(20 \mathrm{~A} / 8 \mathrm{CC} / 25 \mathrm{CD} / 47 \mathrm{M})$ & $(43 \mathrm{~A} / 30 \mathrm{CC} / 5 \mathrm{CD} / 22 \mathrm{M})$ \\
T1yr & $24.8 \pm 2.4^{\mathbf{a}, 1}$ & $39.9 \pm 3.3^{\mathbf{b}, 2}$ \\
& $(25 \mathrm{~A} / 20 \mathrm{CC} / 8 \mathrm{CD} / 57 \mathrm{M})$ & $(30 \mathrm{~A} / 10 \mathrm{CC} / 0 \mathrm{CD} / 60 \mathrm{M})$
\end{tabular}

For comparisons within the factor "with/without acrolein (ACR)", subgroups in the row T0 that are labelled with different upper case superscripts (adhesive only) are significantly different $(\mathrm{p}<0.05)$. Subgroups in the row T1yr that are labelled with different lower case superscripts (adhesive only) are significantly different ( $\mathrm{p}<0.05$ ) For comparisons within the factor "storage time", subgroups within the same column that are labelled with the same numerical designators are not significantly different ( $\mathrm{p}>0.05)$.

Percentages of the failure modes (in parentheses) were classified as: A, adhesive; CC, cohesive in resin composite; $\mathrm{CD}$, cohesive in dentine and $\mathrm{M}$, mixed failure.

\subsection{Zymography of dentine extracts}

The pro-form and active form of recombinant human MMP-2 and -9 for the positive control are shown in lane 1 of Fig. 2a. Phosphoric acid-demineralised dentine extracts contained multiple forms of gelatinolytic enzymes, including a $72 \mathrm{kDa}$ MMP-2 pro-form, a fainter $86 \mathrm{kDa}$ band corresponding to the active form of MMP-9, and other minor gelatinolytic bands (Fig. 2a, lane 2). Pre-treatment of demineralised dentine powder with $0.01 \mathrm{wt} \%$ ACR resulted in almost complete inactivation of the pro-form and active form of MMP-2 and the active form of MMP-9 (Fig. 2a, lane 3). A band around $100 \mathrm{kDa}$ was still detectable, which could be attributed to a complex pro-form of MMP-9. Densitometric evaluation of the zymography bands (Fig. 2b) confirmed that ACR inactivated the pro-form and active form of MMP-2. A band around $100 \mathrm{KDa}$ was still present, although it had a lower intensity compared to the MMP-9 active form. Control zymograms produced by incubating the phosphoric acid-demineralised dentine powder with $2 \mathrm{mM}$ of 1,10-phenanthroline showed no enzymatic activity (data not shown).

\subsection{In-situ zymography of resin-dentine interfaces}

Confocal laser scanning microscopy images of in-situ zymography and superimposition of the fluorescence with light microscopy of the resin-dentine interfaces are shown in Fig. 3. Specimens that were pretreated with $0.01 \mathrm{wt} \%$ ACR prior to adhesive application exhibited minimal green fluorescence within the hybrid layer (Fig. 3a and c). In contrast, specimens that were bonded using the dentine adhesive alone (control) exhibited intense green fluorescence within the hybrid layer (Fig. 3b and d). Quantification of the fluorescence of the specimens (Fig. 3e) indicates a $42.76 \%$ reduction in enzymatic activity when the ACR-based primer was used before the bonding procedure. The difference between the control and experimental group is statistically significant $(\mathrm{p}<0.05)$.

\section{Discussion}

In the present study, ACR was used as a collagen cross-linker during dentine bonding procedures. Application of ACR before bonding to acid-etched dentine resulted in comparatively better preservation of the $\mu$ TBS after one year of in vitro ageing. Hence the first null hypothesis that "ACR as a collagen cross-linker has no effect on bond strength deterioration over time" has to be rejected. Based on the results derived from zymography of the dentine extracts and in-situ zymography of the resin-dentine interfaces, the use of an ACR primer decreased the enzymatic activity of MMPs in the exposed collagen matrix. Thus, the 
70

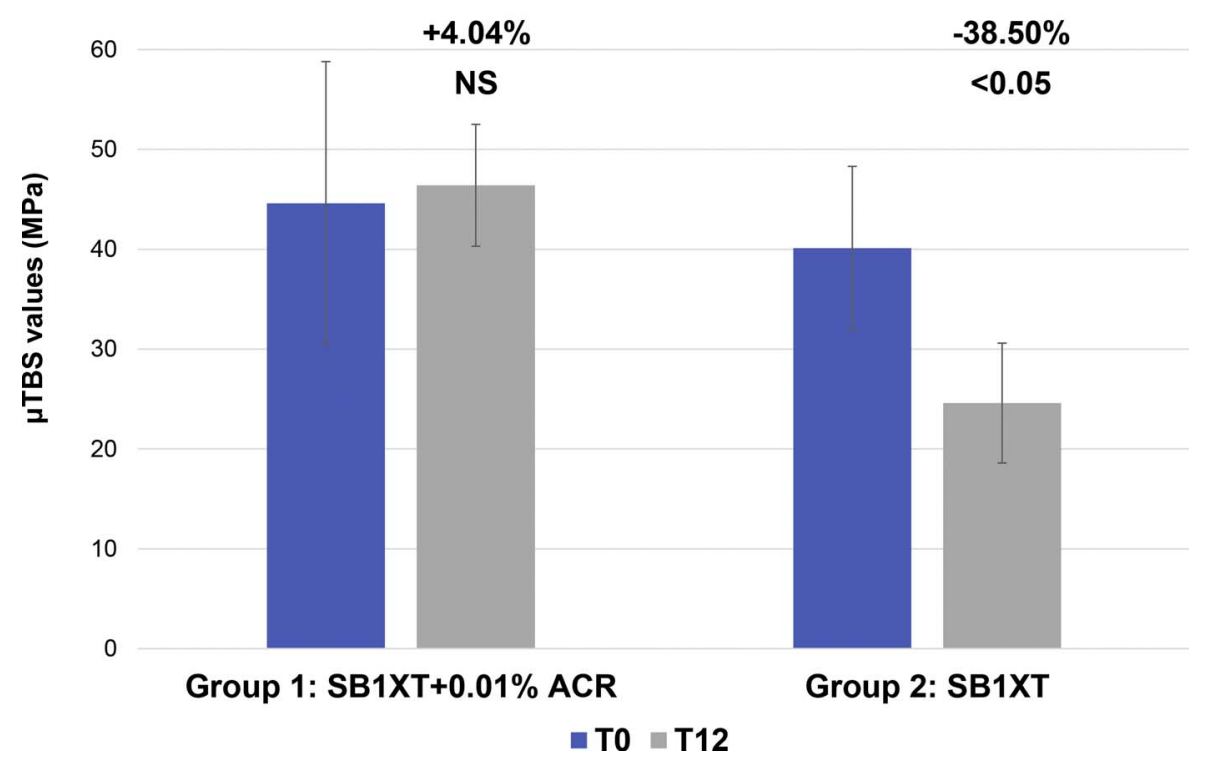

Fig. 1. Graph summarizing the bond strength values (MPa) reported in Table 1.

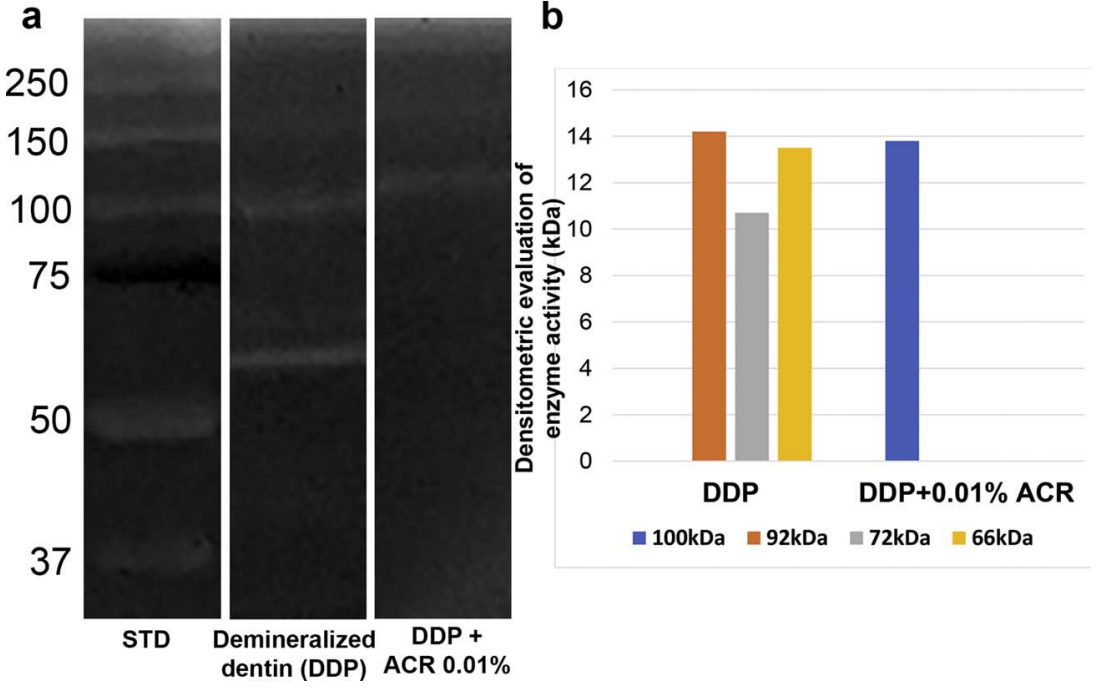

Fig. 2. (a) Acrolein zymographic analysis. Lane 1: demineralized dentin powder showing activity of pro- form of MMP-9 (92 kDa) and active form of MMP-2 (66 kDa). Lane 2: demineralized dentin powder after incubation with $0.01 \%$ ACR showing complete inactivation of MMP-2, and reduced MMP-9 activity, although a complex form of MMP-9 around $100 \mathrm{kDa}$ is still detectable; (b) Graph illustrating the densitometric evaluation of bands obtained from the zymographic analysis of proteins extracted from dentin powder. second null hypothesis that "ACR as a collagen cross-linker has no effect on inactivation of endogenous dentine MMPs" has to be rejected.

The advantage of using cross-linking instead of MMPs inhibitors to preserve the integrity of the exposed collagen matrix within the hybrid layer is that the covalent cross-links formed by cross-linking agents are permanent, whereas inhibitors that are not covalently bonded with the polymerised resin network may leach out of the hybrid layer after 18-24 months [16-18]. Cross-linking agents increase collagen stiffness by creating interfibrillar and intrafibrillar cross-links, thereby strengthening the collagen network structure [25]. This may prevent unravelling of the triple helix of collagen molecules, which is necessary for exposure of the catalytic site of the MMPs to cleave the collagen molecule. This results in the increase in resistance of the collagen matrix to MMP activities [26]. Several studies have investigated the effect of cross-linking agents, including glutaraldehyde, on the mechanical properties of the dentine organic matrix, as well as on the preservation of the hybrid layer $[11,12,15,27-33]$. Glutaraldehyde improves the mechanical properties and reduces the degradation rate of biological tissues [34,35]. Glutaraldehyde increases type I collagen covalent bonding by bridging the amino groups of lysine and hydroxylysine residues of different collagen polypeptide chains with monomeric or oligomeric cross-links. The exogenous cross-links introduced by glutaraldehyde improve the mechanical properties of the exposed dentine matrix $[11,19,20,36,37]$. Similarly to glutaraldehyde, ACR is used as a tissue fixative and is a well-known cross-linking agent [38,39]. Hence, ACR was included in the present experiments to investigate the influence of a simple unsaturated aldehyde molecule on cross-linking of demineralised dentine. ACR is the most reactive $\alpha, \beta$-unsaturated aldehyde. Therefore, it can easily bind to glutathione, as well as react with cysteine, histidine and lysine protein residues. The ACR cross-linking reaction starts with two molecules of ACR that react with the free amino terminal groups of lysine (or hydroxylysine), forming $\mathrm{N} \varepsilon$-(3formyl-3,4-dehydropiperidino)lysine (FDP-lysine). The electrophilic $\alpha, \beta$-unsaturated carbonyl moiety is retained in FDP-lysine, allowing it to react further with sulfhydryl compounds of glutathione, creating new intra- and inter-molecular cross-links [40]. Similarly, carbodiimides, another group of cross-linking agents can form amide bonds between the carboxylic and amino groups on collagen molecules. However, they do not take part in the linkage, and are therefore zero-length crosslinkers [34]. Diversely, other widely investigated cross-linking agents, such as proanthocyanidin-rich compounds, have the ability to form hydrogen bonds between the protein amide carbonyl and the phenolic 

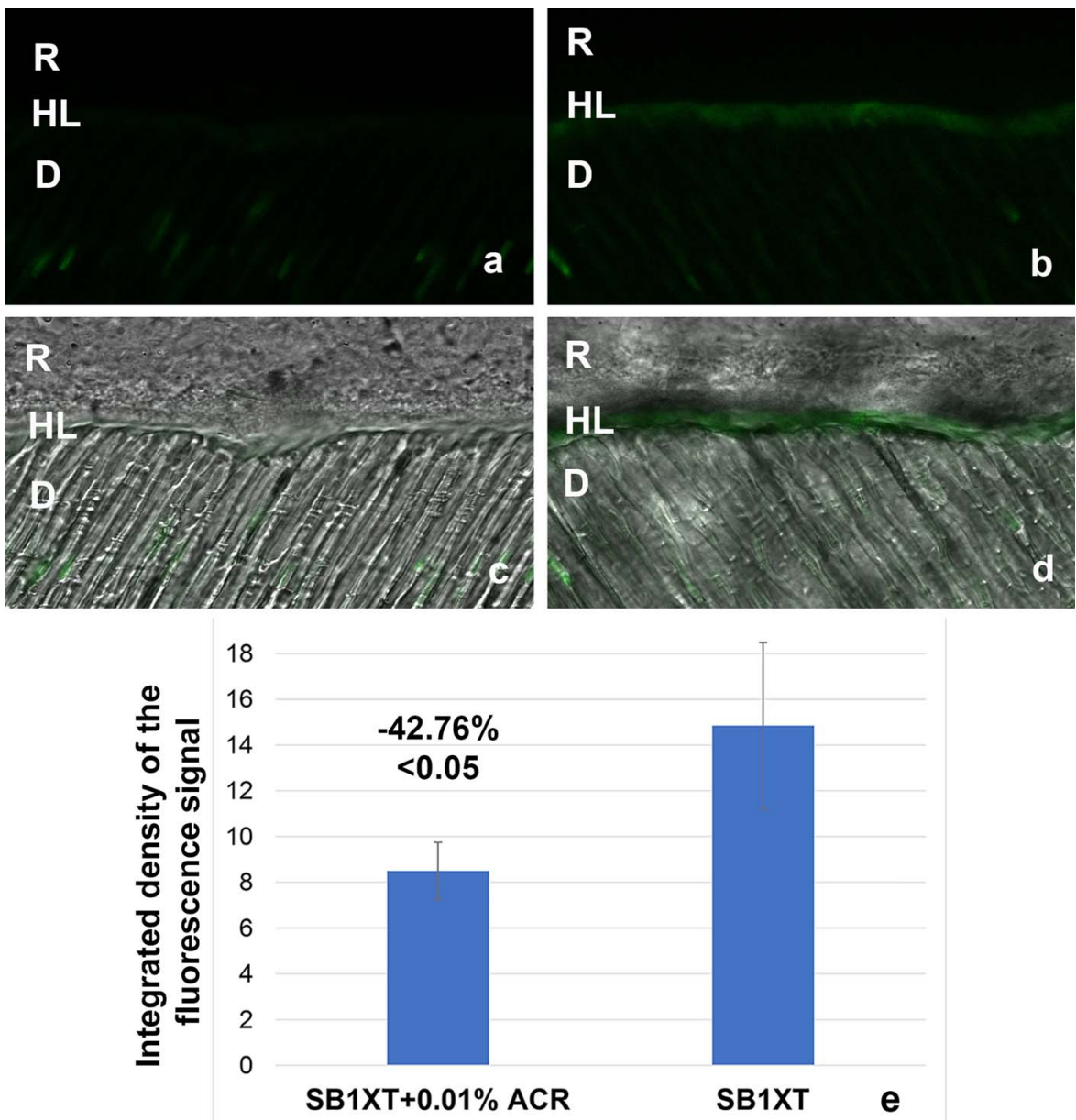

hydroxyl group [25].

In the present study ACR was applied on dentine for $1 \mathrm{~min}$, a very short time when compared to the use of other cross-linking agents such as glutaraldehyde which involve much longer application time $[11,20,37,41]$. Even when ACR was applied for only $1 \mathrm{~min}$, the bond strength of the tested adhesive was preserved after one year. Hence, the results of the present study may be considered to be more clinically relevant when compared to glutaraldehyde, which requires $1 \mathrm{~h}$ of application on the dentin surface to be effective $[37,41]$.

Apart from the creating exogenous cross-links within the dentine collagen matrix, bond preservation in acid-etched dentine that is treated with cross-linking agents may also be related to the ability of the cross-linking agents to inactivate endogenous MMPs in the exposed dentine collagen matrix $[7,18,42]$. It has been hypothesised that crosslinking agents alter the three-dimensional conformation of the catalytic domain of MMPs, or change their negatively-charged ionised carboxyl groups into positively-charged amide groups, to inactivate the MMPs. The advantage of inactivating proteolytic enzymes in the dentine matrix by cross-linking is that it is a non-specific mechanism [43,44]. These cross-links involve covalent bonds that are stable over time. Because MMPs do not turn over in dentine, their inactivation by crosslinking agents should last for a long time and may be even more effective than MMP inhibitors. The zymographic results of the present study support the speculation that stabilisation of hybrid layers created after priming with ACR is related to the inactivation of dentine gelatinolytic activities. Several authors $[45,46]$ have hypothesised that enzyme inactivation involves modification of Cys residues critical for the catalytic site, but no definitive structure characterisation or molecular dynamics simulation have been provided. Hence, the inactivation capability of ACR may be associated with the modification of Cys
Fig. 3. Resin-bonded dentin interfaces prepared with SB1XT with or without ACR pre-treatment, incubated with quenched fluorescein-labelled gelatin; (a) Image acquired in green channel, showing fluorescence (identifying intense endogenous enzymatic activity) in dentinal tubules and within the HL created with SB1XT with ACR pre-treatment; (b) Image acquired in green channel of the HL created by the application of SB1XT to acid-etched dentin without ACR pretreatment showing higher fluorescence; (c) Image of SB1XT with ACR pre-treatment, obtained by merging differential interference contrast image (showing the optical density of the resin-dentin interface) and image acquired in green channel (showing enzymatic activity); (d) Image of HL created with SB1XT without ACR pre-treatment obtained by merging differential interference contrast image and image acquired in green channel; (e) Graph illustrating the quantification of the enzymatic activity of the tested groups. $S B 1 X T=$ Adper $\quad$ Scotchbond $1 \quad \mathrm{XT} ; \quad A C R=$ Acrolein $D=$ Dentin; $H L=$ Hybrid Layer; $R=$ Resin Composite. (For interpretation of the references to colour in this figure legend, the reader is referred to the web version of this article.) residues in the MMPs, which, in turn, results in the inactivation of these proteolytic enzymes. In-situ zymography of the resin-dentine interfaces also confirmed that ACR is efficient in inactivating endogenous enzymes, since a decrease in MMP activity was observed in demineralised dentine treated with ACR. Nevertheless, enzymatic activity was detected in the ACR-treated dentin at around $100 \mathrm{kDa}$ (Fig. 2a, lane 3). This activity may be ascribed to the presence of a pro-MMP-9 complex.

Similar to glutaraldehyde, a disadvantage of ACR compared to the other cross-linking agents is the cytotoxicity that may arise from residues of unreacted or degraded cross-linking agents [32]. Although ACR possesses severe cellular toxicity that is similar to other aldehydes, ACR is ubiquitously present in cooked foods as well as in the environment [40]. Due to its intrinsic cytotoxicity, a very low concentration of ACR was employed $(0.01 \%)$ in the present study. Studies on the adverse effect of chronic ACR ingestion have been performed on rats, and general recommendations for the safety level of ACR ingestion have been published by the U.S. Environmental Protection Agency [47]. The no-observed-adverse-effect-level (NOAEL) of ACR is $0.05 \mathrm{mg} / \mathrm{kg}$ per day. Hence, after the application of a total uncertainty factor of 100 , the recommended reference dose (RfD) is $0.0005 \mathrm{mg} / \mathrm{kg}$ per day. The World Health Organisation suggests a tolerable ACR intake of $0.0075 \mathrm{mg} / \mathrm{kg}$ per day [48]. One drop of the solution that was used in the present study contains $0.05 \mathrm{mg}$ of ACR. This means that the ACR primer may be safely used on adults, especially considering that the intake of ACR during dental procedures would be rare. In addition, ingestion of the primer may be completely avoided by placement of a rubber dam during the restorative procedure. Nevertheless, because there are other sources of the ACR in the environment, the toxicity of ACR should be further investigated by testing serial dilutions of ACR on dental pulp stem cells prior to its recommendation for clinical use. 


\section{Conclusions}

Within the limits of the present in vitro study, it may be concluded that cross-linking of demineralised dentine collagen by an acroleinbased primer increases the durability of resin-dentine bonds over time. This is achieved by reinforcement of the adhesive interface and inactivation of dentinal MMPs within a clinically acceptable working time. Further studies are needed to evaluate the cytotoxicity of acrolein in ex vivo cell culture studies as well as in vivo large animal studies.

\section{References}

[1] L. Breschi, A. Mazzoni, A. Ruggeri, M. Cadenaro, R. Di Lenarda, E. De Stefano Dorigo, Dental adhesion review: aging and stability of the bonded interface, Dent. Mater. 24 (2008) 90-101.

[2] Y. Liu, L. Tjäderhane, L. Breschi, A. Mazzoni, N. Li, J. Mao, D.H. Pashley, F.R. Tay, Limitations in bonding to dentin and experimental strategies to prevent bond degradation, J. Dent. Res. 90 (2011) 953-968.

[3] J. Kinney, G.J. Marshall, S. Marshall, Three-dimensional mapping of mineral densities in carious dentin: theory and method, Scanning Microsc. 8 (1994) 197-204.

[4] R. Visse, H. Nagase, Matrix metalloproteinases and tissue inhibitors of metalloproteinases: structure, function, and biochemistry, Circ. Res. 92 (2003) 827-839.

[5] D. Pashley, F. Tay, C. Yiu, M. Hashimoto, L. Breschi, R. Carvalho, Collagen degradation by host-derived enzymes during aging, J. Dent. Res. 83 (2004) 216-221.

[6] M. Carrilho, S. Geraldeli, F. Tay, M. de Goes, R.M. Carvalho, L. Tjäderhane, A.F. Reis, J. Hebling, A. Mazzoni, L. Breschi, D. Pashley, In vivo preservation of hybrid layer by chlorhexidine, J. Dent. Res. 86 (2007) 529-533.

[7] A. Mazzoni, D.H. Pashley, Y. Nishitani, L. Breschi, F. Mannello, L. Tjäderhane, M. Toledano, E.L. Pashley, F.R. Tay, Reactivation of inactivated endogenous proteolytic activities in phosphoric acid-etched dentine by etch-and-rinse adhesives, Biomaterials 27 (2006) 4470-4476.

[8] A. Mazzoni, P. Scaffa, M. Carrilho, L. Tjäderhane, R. Di Lenarda, A. Polimeni, A. Tezvergil-Mutluay, F.R. Tay, D.H. Pashley, L. Breschi, Effects of etch-and-rinse and self-etch adhesives on dentin MMP-2 and MMP-9, J. Dent. Res. 92 (2013) 82-86.

[9] L. Tjäderhane, F.D. Nascimento, L. Breschi, A. Mazzoni, I.L. Tersariol, S. Geraldeli, A. Tezvergil-Mutluay, M.R. Carrilho, R.M. Carvalho, F.R. Tay, D.H. Pashley, Optimizing dentin bond durability: control of collagen degradation by matrix metalloproteinases and cysteine cathepsins, Dent. Mater. 29 (2013) 116-135.

[10] A.K. Bedran-Russo, G.F. Pauli, S.N. Chen, J. McAlpine, C.S. Castellan, R.S. Phansalkar, T.R. Aguiar, C.M. Vidal, J.G. Napotilano, J.W. Nam, A.A. Leme, Dentin biomodification: strategies, renewable resources and clinical applications, Dent. Mater. 30 (2014) 62-76.

[11] A.K. Bedran-Russo, P.N. Pereira, W.R. Duarte, J.L. Drummond, M. Yamauchi, Application of crosslinkers to dentin collagen enhances the ultimate tensile strength, J. Biomed. Mater. Res. Part B Appl. Biomater. 80 (2007) 268-272.

[12] A.K. Bedran-Russo, D.H. Pashley, K. Agee, J.L. Drummond, K.J. Miescke, Changes in stiffness of demineralized dentin following application of collagen crosslinkers, J. Biomed. Mater. Res. Part B Appl. Biomater. 86 (2008) 330-334.

[13] A.K. Bedran-Russo, C.M. Vidal, P.H. Dos Santos, C.S. Castellan, Long-term effect of carbodiimide on dentin matrix and resin-dentin bonds, J. Biomed. Mater. Res. B Appl. Biomater. 94 (2010) 250-255.

[14] A. Cova, L. Breschi, F. Nato, A. Ruggeri, M. Carrilho, L. Tjäderhane, C. Prati, R. Di Lenarda, F. Tay, D. Pashley, A. Mazzoni, Effect of UVA-activated riboflavin on dentin bonding, J. Dent. Res. 90 (2011) 1439-1445.

[15] R. Seseogullari-Dirihan, F. Apollonio, A. Mazzoni, L. Tjäderhane, D. Pashley, L. Breschi, A. Tezvergil-Mutluay, Use of crosslinkers to inactivate dentin MMPs, Dent. Mater. 32 (2016) 423-432.

[16] A. Mazzoni, V. Angeloni, F.M. Apolonio, N. Scotti, L Tjäderhane, A. TezveroilMutluay, R. Di Lenarda, F.R. Tay, D.H. Pashley, L. Breschi, Effect of carbodiimide (EDC) on the bond stability of etch-and-rinse adhesive systems, Dent. Mater. 29 (2013) 1040-1047.

[17] Y. Liu, V. Dusevich, Y. Wang, Proanthocyanidins rapidly stabilize the demineralized dentin layer, J. Dent. Res. 92 (2013) 746-752.

[18] A. Mazzoni, F.M. Apolonio, V.P. Saboia, S. Santi, V. Angeloni, V. Checchi, R. Curci, R. Di Lenarda, F.R. Tay, D.H. Pashley, L. Breschi, Carbodiimide inactivation of MMPs and effect on dentin bonding, J. Dent. Res. 93 (2014) 263-268.

[19] G.V. Macedo, M. Yamauchi, A.K. Bedran-Russo, Effects of chemical cross-linkers on caries-affected dentin bonding, J. Dent. Res. 88 (2009) 1096-1100.

[20] A. Al-Ammar, J.L. Drummond, A.K. Bedran-Russo, The use of collagen cross-linking agents to enhance dentin bond strength, J. Biomed. Mater. Res. B Appl. Biomater. 91 (2009) 419-424.

[21] J. Van Overbeek, W.J. Huges, R. Blondeau, Acrolein for the control of water weeds and disease-carrying water snails, Science 1129 (1959) 335-336.

[22] D. Arntz, A. Fischer, M. Höpp, S. Jacobi, J. Sauer, T. Ohara, T. Sato, N. Shimizu, H. Schwind, Acrolein and Methacrolein, Ullmann's Encyclopedia of Industrial
Chemistry, Wiley-VCH, Weinheim, 2012.

[23] T. Ishii, T. Yamada, T. Mori, S. Kumazawa, K. Uchida, T. Nakayama, Characterization of acrolein-induced protein cross-links, Free Radic. Res. 41 (2007) 1253-1260.

[24] P.C. Burcham, A. Raso, C. Thompson, D. Tan, Intermolecular protein cross-linking during acrolein toxicity: efficacy of carbonyl scavengers as inhibitors of heat shock protein-90 cross-linking in A549 cells, Chem. Res. Toxicol. 20 (2007) 1629-1637.

[25] A. Frassetto, L. Breschi, G. Turco, G. Marchesi, R. Di Lenarda, F.R. Tay, D.H. Pashley, M. Cadenaro, Mechanisms of degradation of the hybrid layer in adhesive dentistry and therapeutic agents to improve bond durability - a literature review, Dent. Mater. 32 (2016) e41-e53.

[26] L. Chung, D. Dinakarpandian, N. Yoshida, J.L. Lauer-Fields, G.B. Fields, R. Visse, H. Nagase, Collagenase unwinds triple-helical collagen prior to peptide bond hydrolysis, EMBO J. 23 (2004) 3020-3030.

[27] C. Chen, C. Mao, J. Sun, Y. Chen, W. Wang, H. Pan, R. Tang, X. Gu, Glutaraldehydeinduced remineralization improves the mechanical properties and biostability of dentin collagen, Mater. Sci. Eng. C 67 (2016) 657-665.

[28] V. Hass, I.V. Luque-Martinez, M.F. Gutierrez, C.G. Moreira, V.B. Gotti, V.P. Feitosa, G. Koller, M.F. Otuki, A.D. Loguercio, A. Reis, Collagen cross-linkers on dentin bonding: stability of the adhesive interfaces, degree of conversion of the adhesive, cytotoxicity and in situ MMP inhibition, Dent. Mater. 32 (2015) 732-741.

[29] R. Liu, M. Fang, Y. Xiao, F. Li, L. Yu, S. Zhao, L. Shen, J. Chen, The effect of transient proanthocyanidins preconditioning on the cross-linking and mechanical properties of demineralized dentin, J. Mater. Sci. Mater. Med. 22 (2011) 2403-2411.

[30] N. Hiraishi, R. Sono, I. Sofiqul, C. Yiu, H. Nakamura, M. Otsuki, T. Takatsuka, J. Tagami, In vitro evaluation of plant-derived agents to preserve dentin collagen, Dent. Mater. 29 (2013) 1048-1054.

[31] C. Xu, Y. Wang, Cross-linked demineralized dentin maintains its mechanical stability when challenged by bacterial collagenase, J. Biomed. Mater. Res. B Appl. Biomater. 96 (2011) 242-248.

[32] B. Han, J. Jaurequi, B.W. Tang, M.E. Nimni, Proanthocyanidin: a natural crosslinking reagent for stabilizing collagen matrices, J. Biomed. Mater. Res. A 65 (2003) 118-124.

[33] J. Zhou, A. Chiba, D.L.S. Scheffel, J. Hebling, K. Agee, J. Tagami, J. Tan, D. Abuelenain, M.A. Nawareg, A.H. Hassan, L. Breschi, F.R. Tay, D.H. Pashley, Cross-linked dry bonding: a new etch-and-rinse technique, Dent. Mater. 32 (2016) 1124-1132.

[34] M.E. Nimni, The cross-linking and structure modification of the collagen matrix in the design of cardiovascular prosthesis, J. Card. Surg. 3 (1988) 523-533.

[35] H.W. Sung, Y. Chang, C.T. Chiu, C.N. Chen, H.C. Liang, Crosslinking characteristics and mechanical properties of a bovine pericardium fixed with a naturally occurring crosslinking agent, J. Biomed. Mater. Res. 47 (1999) 116-126.

[36] K. Adkins, Acrolein fixation for light microscopy of dental tissues, Arch. Oral Biol. 15 (1970) 1255-1262.

[37] P. Dos Santos, S. Karol, A.K. Bedran-Russo, Long-term nanomechanical properties of biomodified dentin- resin interface components, J. Biomech. 44 (2011) 1691-1694.

[38] D. Cheung, N. Perelman, E. Ko, M. Nimni, Mechanism of crosslinking of proteins by glutaraldehyde III: reaction with collagen in tissues, Connect. Tissue Res. 13 (1985) 109-115.

[39] D. Cheung, D. Tong, N. Perelman, D. Ertl, M. Nimni, Mechanism of crosslinking of proteins by glutaraldehyde IV: in vitro and in vivo stability of a crosslinked collagen matrix, Connect. Tissue Res. 25 (1990) 27-34.

[40] J.F. Stevens, C.S. Maier, Acrolein Sources, metabolism, and biomolecular interactions relevant to human health and disease, Mol. Nutr. Food Res. 52 (2008) 7-25.

[41] C.S. Castellan, P.N. Pereira, R. Helena, M. Grande, A.K. Bedran-Russo, Mechanica characterization of proanthocyanidin-dentin matrix interaction, Dent. Mater. 26 (2010) 968-973.

[42] Y. Nishitani, M. Yoshiyama, B. Wadgaonkar, L. Breschi, F. Mannello, A. Mazzoni, R. Carvalho, L. Tjäderhane, F. Tay, D. Pashley, Activation of gelatinolytic/collagenolytic activity in dentin by self etching adhesives, Eur. J. Oral Sci. 114 (2006) $160-166$.

[43] I.L. Tersariol, S. Geraldeli, C.L. Minciotti, F.D. Nascimento, V. Pääkkönen, M.T. Martins, M.R. Carrilho, D.H. Pashley, F.R. Tay, T. Salo, L. Tjäderhane, Cysteine cathepsins in human dentin-pulp complex, J. Endod. 36 (2010) 475-481.

[44] F.D. Nascimento, C.L. Minciotti, S. Geraldeli, M.R. Carrilho, D.H. Pashley, F.R. Tay, H.B. Nader, T. Salo, L. Tjäderhane, I.L. Tersariol, Cysteine cathepsins in human carious dentin, J. Dent. Res. 90 (2011) 506-511.

[45] G. Aldini, M. Orioli, M. Carini, Protein modification by acrolein: relevance to pathological conditions and inhibition by aldehyde sequestering agents, Mol. Nutr. Food Res. 55 (2011) 1301-1319.

[46] A. Gugliucci, N. Lunceford, E. Kinugasa, H. Ogata, J. Schulze, S. Kimura, Acrolein inactivates paraoxonase 1: changes in free acrolein levels after hemodialysis correlate with increases in paraoxonase 1 activity in chronic renal failure patients, Clin. Chim. Acta 384 (2007) 105-112.

[47] USEPA, IRIS Toxicological review of acrolein, U.S. Environmental Protection Agency, Washington, DC, 2003.

[48] R. Gomes, M.E. Meek, M. Eggleton, Concise International Chemical Assessment Document 43: Acrolein, World Health Organization, Geneva, 2002. 